going on under his supervision, for example, on the decay of turbulence and aerodynamic noise.

Chemistry at the Chester Beatty Research Institute : Prof. F. Bergel

Dr. Franz Bergel has been appointed to the chair of chemistry in the Institute of Cancer Research (University of London), tenable at the Chester Beatty Research Institute of the Royal Cancer Hospital, in succession to the late Prof. G. A. R. Kon. Prof. Bergel was born in Vienna, where he received his early education before proceeding to higher studies in chemistry and physiological chemistry at the Universities of Würzburg and Freiburg im Breisgau. In Freiburg, he worked under Prof. $\mathrm{H}$. Wieland, on the oxidation of amino-acids and their alkyl derivatives, and during 1927-33 acted as head of the Department of Medical Chemistry in the Institute of Chemistry. Both there and on a visit to University College, Colombo, he pursued an investigation of the active principle of Indian hemp, work which was later continued in collaboration with Prof. A. R. Todd at the Lister Institute and completed by the researches of Prof. Todd in Great Britain and of Prof. Roger Adams in the United States. Arriving in Britain in 1933, Prof. Bergel worked for three years in the Department of Medical Chemistry in the University of Edinburgh, under the late Prof. George Barger. There, and afterwards in the Lister Institute under Prof. R. Robison, Prof. Bergel collaborated with Prof. Todd and Dr. T. Work in studies of the structure and synthesis of vitamins $B_{1}$ and E. From 1938 until early this year, Prof. Bergel was director of research for Roche Products, Ltd., and since 1946 has been honorary lecturer in the Department of Pharmacology at University College, London. During this period he has carried out work on vitamins, analgesics, parasympathomimetic and spasmolytic agents, ganglion and neuromuscular blocking substances, antibiotics including penicillin and patulin, and organic phosphate compounds such as cocarboxylase, adenine phosphates, etc. On these and other topics he is the author of some eighty papers in the chemical literature. Although Prof. Bergel has not hitherto worked on the problems of cancer, his wide knowledge and experience of the chemistry of biological systems should enable him to make a most valuable contribution in his new field.

\section{Queen's University of Belfast: Appointments}

Tнв Senate of the Queen's University of Belfast has made the following joint appointments with the Northern Ireland Hospitals Authority: Dr. J. J. Pritchard, reader in human anatomy in the University of London, to the chair of anatomy; Dr. G. MacG. Bull, lecturer in medicine at the Postgraduate Medical School, London, to the chair of medicine.

Dr. Pritchard graduated at the University of Adelaide and went to Magdalen College, Oxford, with a Rhodes Scholarship in 1935. He obtained firstclass honours in physiology and completed a medical course at St. Bartholomew's Hospital in 1940. He has been successively demonstrator, assistant lecturer, senior lecturer and reader in anatomy in the University of London, at St. Mary's and St. Rartholomew's Hospitals.

Dr. Bull graduated in medicine at the University of Cape Town. After extensive experience of clinical work and undergraduate teaching in South Africa, he went with a fellowship to the British Postgraduate School of Medicine, and since 1947 has been physician to the Hammersmith Hospital and lecturer in medicine in the Postgraduate School. Dr. Bull has done very distinguished work on the kidney and is a recognized authority in this field. The professorship of medicine is a full-time appointment. The responsibilities of the chair include a professorial unit for clinical research, in the new medical block which is nearing completion at the Royal Victoria Hospital.

\section{Leverhulme Research Fellowships}

ThE Trustees of the Leverhulme Research Fellowships have approved the following awards, among others, for research on the subjects mentioned, tenable for periods up to two years: Fellowships: Mr. D. Meredith (Roman archæology of the Eastern Desert of Egypt); Dr. D. C. Pepper, Trinity College, Dublin (role of solvent in chemical reactions); Mr. J. W. S. Pringle, lecturer in zoology, University of Cambridge (neurological researches on tropical insects in Ceylon); Dr. F. Smithies, lecturer in mathematics, University of Cambridge (applications of functional analysis); Prof. A. J. B. Wace, latəly professor of classics, Farouk I University, Alexandria (Mycenæ: the civilization of the Aegean Bronze Age); Prof. H. T. Wade-Gery, Wykeham professor of ancient history, University of Oxford (interaction of Greek and Persian civilizations in the early Achæmenid period). Research Grants: $\mathrm{Mr}$. F. L. Bartels, Mfantsipim School, Gold Coast (emergence and development of higher education in the Gold Coast) ; Mr. P. H. Davis, lecturer in taxonomic botany, University of Edinburgh (biological exploration of mountainous regions in T'urkey); Dr. H. T. Drever, lecturer in geology, University of St. Andrews (a petrographical and geochemical study of the tertiary igneous complex in West Greenland); Mr. N. G. L. Hammond, Clare College, Cambridge (archæology and topography of Ancient Epirus); Miss K. M. Kenyon, director, British School of Archæology in Jerusalem (chronology and culture of Jericho in the Neolithic and Bronze Ages); Mr. J. W. Wright, inspector of surveys, Sudan Government (hydrology of the River Sobat and its relation with the White Nile).

\section{Oceanographical Research Work Aboard the R.R.S. Discovery II}

ThE National Oceanographic Council's research ship R.R.S. Discovery $I I$ is now engaged on work in the Atlantic, using Plymouth as its home port, and the present voyage, which is expected to last a month, is devoted principally to the study of the growth and decay of waves and wind-drifts. The ship has been fitted with a new type of wave-recorder, specially designed at the National Institute of Oceanography, which measures the variations of pressure at two points below the water-line on opposite sides of the ship's hull and at the same time measures the up-and-down movements of the ship at these two points. By such means the pattern of wave-trains arriving at the ship when it is hove-to can be fairly accurately recorded despite the movement of the ship itself, which at times may be quite considerable. Wind-drifts will be measured by towing electrodes behind the ship and estimating the drift of the electrodes and ship at right-angles to its course from the small E.M.F. induced by the drift through the earth's magnetic field of the sea water and the wire connecting the electrodes. This idea is a very old one : measurements using the same basic principles were 